\title{
Elemental metabolomics
}

\author{
Ping Zhang ${ }^{1}$, Constantinos A. Georgiou ${ }^{2}$ and Vladimir Brusic ${ }^{1,3}$ \\ ${ }^{1}$ Menzies Health Institute Queensland, Griffith University, Gold Coast, QLD Australia \\ ${ }^{2}$ Chemistry Laboratory, Department of Food Science and Human Nutrition, Agricultural \\ University of Athens, Athens, Greece \\ ${ }^{3}$ School of Medicine and Bioinformatics Center, Nazarbayev University, Astana, Kazakhstan
}

Corresponding author: Vladimir Brusic, School of Medicine and Bioinformatics Center, Nazarbayev University, Astana, Kazakhstan; E-mail: brusicv@gmail.com

Ping Zhang is a Research Fellow at Menzies Health Institute Queensland, Griffith University Australia. Her research interests focus on bioinformatics and health informatics. She develops and applies pattern recognition, machine learning and statistical analysis in biomedicine.

Constantinos Georgiou is a Professor of Analytical Chemistry in the Department of Food Science and human nutrition at the Agricultural University of Athens, Greece. He is interested in food authentication with an emphasis on food adulteration and determination of food origin. He has been developing analytical technologies based on luminescence spectroscopy and elemental mass spectrometry.

Vladimir Brusic is a Professor at School of Medicine and the Director of Bioinformatics Center at Nazarbayev University, Astana, Kazakhstan. He is also a Professor at Menzies Health Institute Queensland, Griffith University, Gold Coast, QLD, Australia. His research interests focus on bioinformatics, health informatics, knowledge management and data analytics in biomedicine. 


\begin{abstract}
Elemental metabolomics is quantification and characterization of total concentration of chemical elements in biological samples and monitoring of their changes. Recent advances in Inductively Coupled Plasma-Mass Spectrometry have enabled simultaneous measurement of concentrations of more than 70 elements in biological samples. In living organisms, elements interact and compete with each other for absorption and molecular interactions. They also interact with proteins and nucleotide sequences. These interactions modulate enzymatic activities and are critical for many molecular and cellular functions. Testing for concentration of more than 40 elements in blood, other bodily fluids and tissues are now in routine use in advanced medical laboratories. In this article we define the basic concepts of elemental metabolomics, summarize standards and workflows, and propose minimum information for reporting the results of an elemental metabolomics experiment. Major statistical and informatics tools for elemental metabolomics are reviewed and examples of applications are discussed. Elemental metabolomics is emerging as important new technology with applications in medical diagnostics, nutrition, agriculture, food science, environmental science, and multiplicity of other areas.
\end{abstract}

Key words: biomonitoring, chemometrics, clinical laboratory testing, ionomics, metallomics, mineralomics

\title{
Key points
}

- Elemental metabolomics is simultaneous quantification and characterization of total concentration of chemical elements in biological samples and monitoring of their changes.

- $\quad$ ICP-MS is increasingly being used for multi-element screening because of its ultra-high sensitivity and selectivity, high-throughput multi-element measuring capability, accurate absolute quantification in complex matrices, easy combination with chromatographic separation methods, its complementarity with organic mass spectrometry, and isotope measuring ability.

- Elemental metabolomics is emerging as important methodology for molecular biology, medical diagnosis, prognosis, and monitoring, toxicology, environmental studies, food safety and traceability, nutrition, and other fields such as forensics and archeology.

- We have defined a template workflow for elemental metabolomics experiment and a corresponding data workflow along with the discussion of the standards for the field, including standard operating procedures, the use of reference materials, and minimum information for reporting results of elemental metabolomics experiments 


\section{Introduction}

A metabolite is a product of chemical processes in an organism or a cell. The concepts of metabolic patterns, individual metabolic patterns, and "hypothetical average individual" were promoted in 1940s [1]. Thanks to the improvements in analytical methods, instrumentation and analytical capabilities, quantitative metabolic profiling of biomedical specimens using mass spectrometry became possible in 1970s [2]. Improvements in instrumentation, molecular methods, cheminformatics and bioinformatics, over the following 30 years, have lead to highthroughput measurement of multiple metabolites in human and plant specimens [3, 4]. The ability to simultaneously measure hundreds of metabolites, with high accuracy, at high speed, and at affordable cost enabled the definition of metabolome and metabolomics. Elemental metabolomics focuses on comprehensive analysis of more than 70 chemical elements in biological samples that represent various biological conditions and states including genetic perturbations, nutritional intervention, disease and disease progression, drug effects, or environmental influences. Key definitions used in metabolomics [5-8] and new definitions in elemental metabolomics are shown in Table 1.

Table 1. Definitions of key concepts and approaches in metabolomics [5-9] and elemental metabolomics.

\begin{tabular}{ll}
\hline TERM & DESCRIPTION \\
\hline Metabolite & $\begin{array}{l}\text { An intermediate or final product of chemical reactions in an organism } \\
\text { or a cell. }\end{array}$ \\
\hline Metabolome & $\begin{array}{l}\text { A complete set of small-molecules (molecular weight <1500 Da), that } \\
\text { exist in a given biological tissues or sample } \\
\text { Quantification of metabolome in target samples, monitoring their } \\
\text { change, and characterization of phenotypes over time or in response } \\
\text { to various stimuli. }\end{array}$ \\
\hline Eetabolomics & $\begin{array}{l}\text { Quantification and characterization of total concentration of chemical } \\
\text { elements in biological samples and monitoring their changes. }\end{array}$ \\
\hline Elemental profiling & Quantification of chemical elements in a given sample or specimen. \\
\hline Elemental fingerprinting & Classification of biological samples using their elemental profiles. \\
\hline Elemental signature & $\begin{array}{l}\text { Elemental composition derived from a representative selection of } \\
\text { samples that represents some condition or status (e.g. geographic } \\
\text { origin, genetic origin, or health status). }\end{array}$ \\
\hline
\end{tabular}


Metabolomics is the endpoint of the Omics cascade (genomics $\rightarrow$ transcriptomics $\rightarrow$ proteomics $\rightarrow$ metabolomics). Omics focuses on high-throughput measurements of molecular data and their interpretations that connect organism's genetic code with the characteristics of its phenotype defining a key component of systems biology [9]. Elemental metabolomics is an interdisciplinary field at the intersection of chemistry, physics, biology, mathematics, and data sciences. The workflow for elemental metabolomics is shown in Figure 1. The design of this workflows was informed by multiple inputs including proposed metabolomics workflows [10, 11], standard operating procedures (SOP) for handling blood and urine for metabolomics studies [12, 13], imaging and speciation analysis methods [14], minimum information reporting standard (MIRS) for results of metabolomics experiments [15], formal determination of reference values of elements [16], and various statistical and machine learning methods used in metabolite screening $[10,11,17]$.

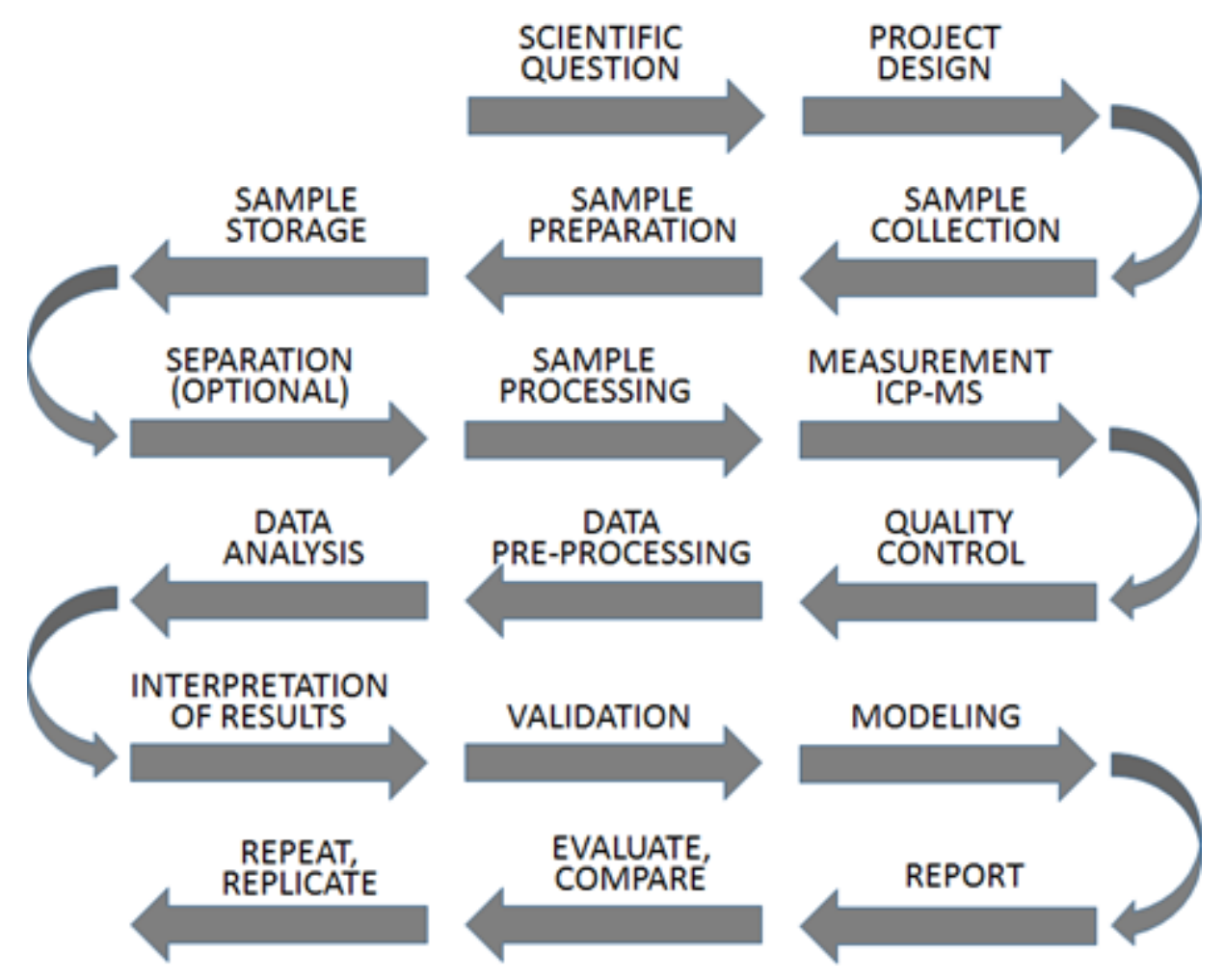

Figure 1. Data workflow within an elemental metabolomics experiment is shown. Each of these steps needs to be properly documented in reports to ensure proper evaluation of results, comparability, and replication of any experiment and ultimately pooling together data from multiple experiments for largescale analyses. The overall workflow can be divided into six steps representing horizontal flow: design $\rightarrow$ sampling $\rightarrow$ analytical chemistry $\rightarrow$ data analytics $\rightarrow$ interpretation/modeling $\rightarrow$ further use. There is a terminology overlap where some words may have different meaning in chemistry and bioinformatics. Additional details about these steps are available in Tables 2 and 3 and throughout the main text. 
The size of actual metabolome for any given organism is unknown and difficult to estimate [18]. As of September 2016 the Human Metabolome Database (HMDB) [19] has some 42,000 metabolite entries. It has been estimated that $>200,000$ metabolites are present in the plant kingdom [6]. Current state-of-the-art of mass spectrometry and separation methods enables routine analysis of up to 1000 metabolites with throughput of 1000 samples per day [20]. Metabolomics produces mega-variate data creating situations where number of variables easily exceeds the number of samples used in a research study resulting in the curse of dimensionality [21]. Such data are difficult to analyze since false correlations and overfitting of statistical models are common while the artefacts of experimental design are amplified. This makes highthroughput metabolomics studies difficult to interpret and there is a need for methodology that can simplify and streamline metabolomics data analysis. The measurement of chemical elements is a logical first step in metabolomics studies that determines the total amount of each element in the sample. These measurements have direct diagnostic value in medicine and can also be used for food authentication and determination of food origin. Furthermore, knowing the total amount of each element in the sample provides useful information for the next metabolomics step that involves screening of thousands of metabolites.

This article provides an overview of elemental metabolomics, a neglected subfield of metabolomics. In the following sections we will describe the basic concept of elemental metabolomics, standards used to ensure accurate and reproducible measurements, methods for data capture and processing, and bioinformatics methods for data analysis and interpretation. We have also reviewed applications related to elemental metabolomics and provided brief comments about bioinformatics tools for these applications.

\section{Elemental Metabolomics}

Approximately $96 \%$ of elemental composition of human body, by mass, consists of four elements (C, $\mathrm{H}, \mathrm{N}$ and $\mathrm{O}$ ), we term them "mega elements". Another $3.25 \%$ consists of macro elements ( $\mathrm{Ca}$, $\mathrm{Cl}, \mathrm{K}, \mathrm{Mg}, \mathrm{Na}, \mathrm{P}$, and $\mathrm{S}$ ), while the remaining elements are called trace ( $\mathrm{Al}, \mathrm{As}, \mathrm{B}, \mathrm{Ba}, \mathrm{Br}, \mathrm{Cd}, \mathrm{Ce}$, $\mathrm{Co}, \mathrm{Cs}, \mathrm{Cu}, \mathrm{Cr}, \mathrm{F}, \mathrm{Fe}, \mathrm{Ge}, \mathrm{Hg}$, I, Li, Mn, Mo, Ni, Pb, Rb, Se, Si, Sn, Sr, Ti, and Zn) or ultratrace (Ag, $\mathrm{Au}, \mathrm{Be}, \mathrm{Bi}, \mathrm{Ga}, \mathrm{Hf}$, In, Ir, Nb, Os, Pd, Pt, Re, Rh, Ru, Sb, Sc, Ta, Tc, Te, Th, TI, U, V, W, Y, Zr, and the 14 lanthanides). Ultratrace elements are present in concentration of roughly 0.1-10 $\mu \mathrm{g}$ per $\mathrm{kg}$ of sample. In practical terms, a human body of $75 \mathrm{~kg}$ would have approximately $72.5 \mathrm{~kg}$ of four mega elements, $2.5 \mathrm{~kg}$ of seven macro elements (Ca and P make $1.9 \mathrm{~kg}$ ), $15 \mathrm{~g}$ of trace (total of 28), and $1 \mathrm{mg}$ of ultra-trace (total of 41) elements [22]. It is not surprising that elemental metabolomics studies are few - until recently the accuracy of measurement and the cost were not at the level that would support its routine use. Our ability to accurately and reproducibly measure ultra-trace elements has realized only in the last 10-15 years. It is only over the last few years that elemental metabolomics studies became affordable. Advances in ICP-MS enabled accurate and affordable measurement of more than 70 elements at reasonable cost [23] (Figure 2). ICP-MS is suitable for elemental metabolomics measurement given its performance 
characteristics including detection limits, concentration working range, sample throughput capacity, and methods for compensation of interferences [24]. Sophisticated methods including matrix removal, mathematical correction equations, and collision/reaction cell ICP-MS has been developed to minimize or nullify the measurement interferences. Interested readers can find more details about ICP-MS use in life sciences in [25].

Large-scale high-throughput elemental profiling studies have been known as ionomics [26, 27], mineralomics $[28,29]$, metallomics [30,31] and elementomics [32]. These high-throughput approaches study the relationships between elemental minerals, metals, or non-metals measured in their elemental form (as total element quantity) in biological samples, and correlate them to physiological states, biological processes, and phenotypes. They refer essentially to the same concept - the role of individual elements in physiology and functioning of an organism. Elemental metabolomics, therefore, describes studies of metabolic role of the comprehensive matrix of multiple elements. Elemental metabolomics shares the scope with metallomics. Metallomics studies "the metallome", that is metals, metalloids, and trace elements in biological systems and the interaction of the metallome with other 'omes' within a given organism. Elemental metabolomics, however, provides a broader and more formal framework as it promotes:

- formalization of standards and procedures including standardized workflows and standard operating procedures developed specifically for elemental metabolomics for different kinds of biological materials

- the use of sample matched reference materials defined for $>70$ elements

- completeness of screening that includes all measurable elements (currently $>70$ )

- use of sophisticated statistical and mathematical modeling tools to extract maximum knowledge from elemental profiles

- concurrent measurement of bioavailability and transfer of elements between the environment, food, and organisms and elemental accumulation in various tissues

Individual elements interact at multiple levels in living organisms including competitive absorption in roots of plants [33] and through mucosal surfaces in animals [34]. They may act as antagonists, synergists, or catalysts [35], can replace each other from their molecular binding sites [36], and interact with various targets to enhance biological effects [37]. The essentiality and toxicity of elements depends on chemical speciation [14, 38]. Chemical speciation is of interest in toxicology and nutrition ( $\mathrm{As}, \mathrm{Ba}, \mathrm{Ca}, \mathrm{Cd}, \mathrm{Co}, \mathrm{Cu}, \mathrm{Pb}, \mathrm{Se}, \mathrm{Sr}, \mathrm{Zn}$ ), environmental exposure (As, $\mathrm{Cd}, \mathrm{Cr}, \mathrm{Fe}, \mathrm{Ge}, \mathrm{Hg}, \mathrm{Pb}, \mathrm{Sb}, \mathrm{Se}, \mathrm{Sn}$ ), industrial exposure (As, $\mathrm{Fe}, \mathrm{Ga}, \mathrm{Hg}, \mathrm{Ni}, \mathrm{Rh}, \mathrm{Ru}, \mathrm{V}$ ), and medically-related exposure ( $\mathrm{Al}, \mathrm{Co}, \mathrm{Cr}, \mathrm{Cu}, \mathrm{Fe}, \mathrm{Mo}, \mathrm{Ni}, \mathrm{Pt}, \mathrm{Ru}, \mathrm{Ti}, \mathrm{Zn}$ ) where toxicity and biological effects depend on chemical species [38]. Differences in toxic effects of elements depend on their chemical forms that exhibit differences in solubility, transport, reactivity, absorbability, and the chemical complexes they form within tissues and cells [39]. For example, chromium is an essential element that comes mainly in form of $\mathrm{Cr}(\mathrm{III})$ that is of low toxicity and $\mathrm{Cr}(\mathrm{VI})$ that is highly toxic [39]. Most forms of mercury $(\mathrm{Hg})$ are highly toxic to humans, particularly to the nervous system. Elemental and inorganic ionic forms of $\mathrm{Hg}$ are poorly absorbed from the gut, but organic forms such as methylmercury ( $\mathrm{MeHg}$ ) are readily absorbed from the gastrointestinal tract and can also readily cross the blood-brain barrier. Industrial pollution commonly discharges $\mathrm{Hg}$ 
in ionic or elemental form. Aquatic organisms convert elemental and ionic $\mathrm{Hg}$ into methylmercury increasing bioavailability to humans mainly through fish and other seafood [40]. In addition to the concerns about arsenic and cadmium in rice it was suggested that rice may be another significant source of dietary MeHg [41]. Toxic element exposure, therefore, requires elemental assessment in complex matrices spanning multiple nutritional to various environmental or occupational sources.

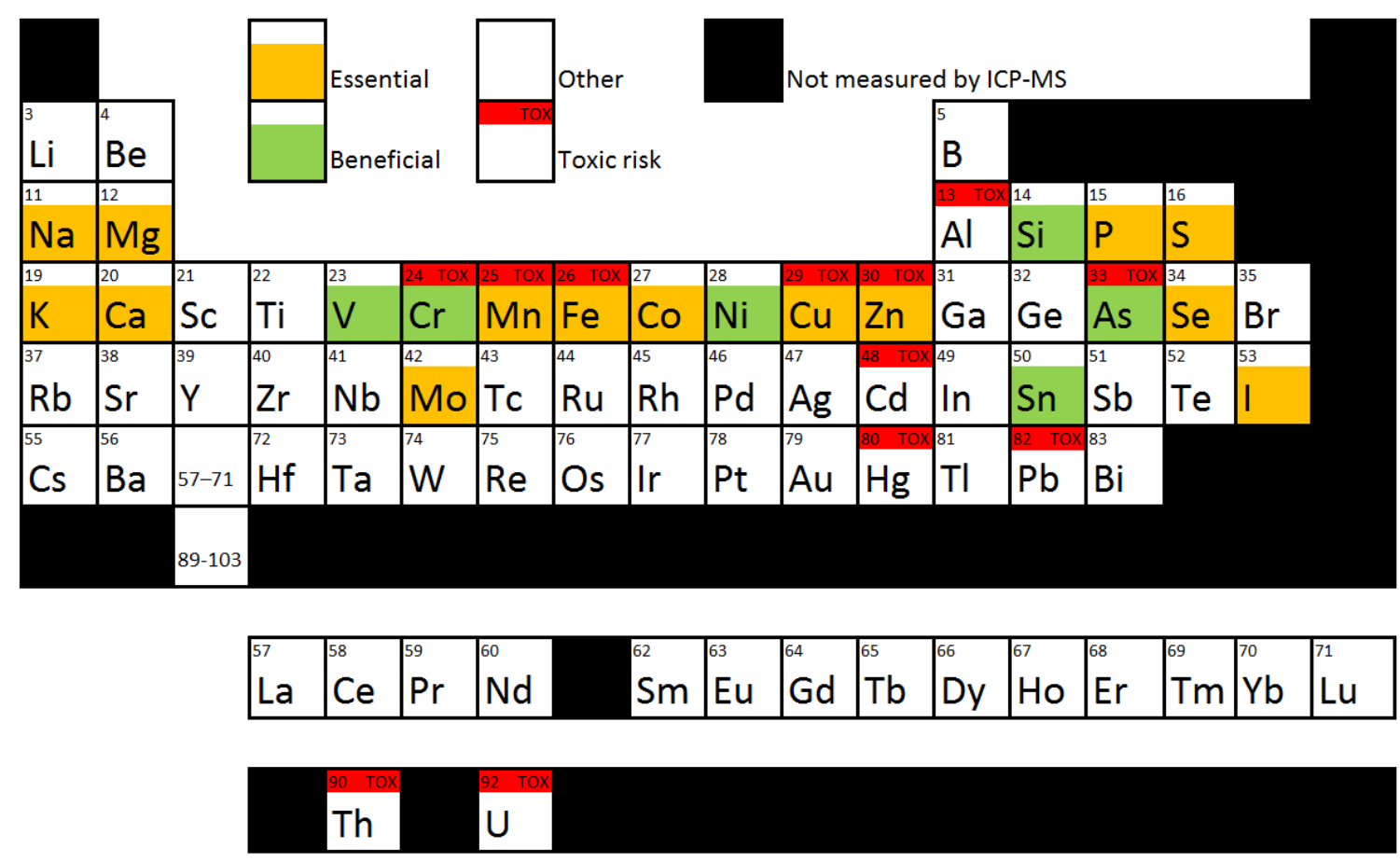

Figure 2. Common elemental analytes detectable and measurable by ICP-MS are shown. Groupings into essential, beneficial, common without clearly defined function, and toxic elements are somewhat arbitrary and need to be taken within a specific biological context. Elements labeled as either essential or beneficial are either the components of major structural components in the body (Ca, P, S); responsible for maintenance of ionic equilibria, activation, or signaling ( $\mathrm{Ca}, \mathrm{K}, \mathrm{Mg}, \mathrm{Na}$ ); components of enzymes or hormones (Co, Cr, Cu, Fe, I, Mn, Mo, Ni, Se, Sn, V, Zn). Essential and beneficial (suggested that may be essential) are designated as given in [127]. For example, several elements display essentiality-toxicity duality. In chromium, this duality is related to speciation - trivalent $\mathrm{Cr}$ (III) is an essential nutrient considered non-toxic, while hexavalent $\mathrm{Cr}(\mathrm{VI})$ is considered toxic and carcinogenic. Elements indicated as "toxic risk" are those reported as "high toxic risk" [128], implicated as neurotoxic [129], or are radioactive.

Isotopes represent forms of a given chemical element. Isotopes of an element have identical number of protons, but differ in the number of neutrons in each atom. The natural abundance of isotopes at a given point of time is relatively stable, but small variations may characterize the source, e.g. oceans vs. soils, or different geographic locations [42, 43]. Isotopic abundance patterns are used for mega elements $(\mathrm{C}, \mathrm{H}, \mathrm{N}$, and $\mathrm{O}$ ) and also $\mathrm{Br}, \mathrm{F}, \mathrm{P}, \mathrm{S}$, and Si [44]. Isotope screening is used for identification of food origin, including geographic region and production 
system (e.g. organic vs conventional) [45]. Stable isotope analysis refers to the determination of isotopic abundances. Isotopic compositions of samples, reflect their biological or physical provenance and history and thus provide additional discriminating tool for samples that have similar elemental signatures. Current practice does not define criteria for preference of elemental signatures over isotopic profiles or the reverse. We anticipate that in future more comprehensive measurements including isotopes will be performed; currently these measurements are limited by the cost of high-resolution mass spectrometry. The list of stable isotopes is provided in Table S1, Supplementary Information [137]. Despite that only 73 elements (Figure 2) and low-abundance isotopes of $\mathrm{C}, \mathrm{H}, \mathrm{N}$, and $\mathrm{O}$ can be measured, taking into account isotopes, speciation, and mutual interactions of elements, variation of elemental metabolomics is of high combinatorial complexity. Furthermore, elemental metabolomics is emerging as important methodology for molecular biology, medical diagnosis, prognosis, and monitoring, toxicology, environmental studies, food safety and traceability, nutrition, and other fields such as forensics and archeology. Variation of biologically relevant samples is huge - it is affected by the source, origin, season, geographic location, health status, and other variables. Individual studies having tens of thousands of samples will soon become the norm. Statistical and bioinformatics methods are essential for elemental metabolomics. Some of these methods can be adapted from metabolomics, laboratory science, and food science, while new methods are needed to deal with the specific needs of elemental metabolomics.

\section{Standards and minimum information for elemental metabolomics}

To ensure validity, analytical measurements using biological matrices must adhere to SOP in both pre-analytical and analytical steps. A particular problem is presented with ultra-trace elements. Elements that are used or are present in equipment and materials that are used in pre-analytical and analytical steps represent major potential sources of contamination. Pre-analytical SOP ensure that sample collection and handling preserve the integrity and the content of the samples before the analytical step is performed [46]. Analytical SOP must ensure that elemental content during preparation and measurement steps is not compromised. SOP prescribe the use of reference standards including blanks, instrument calibration standards, and internal standards and ensure the selectivity, accuracy, precision, integrity, and stability of the measurement method $[47,48]$. Blood collection and handling require appropriate accessories and procedures (flasks, tubes, needles, reagents) to prevent contamination and SOP in this area are well-defined [49]. SOP for other areas of biomonitoring, such as food do exist [e.g. 50, 51]. Given the wide variety of biological samples it is necessary that SOP are developed for each type of biological sample.

Prevention of sample contamination with trace and ultra-trace elements requires clean handling and clean laboratory environment. Ideally, an ISO Class 5 (ISO Guide 14644, equivalent to FED STD 209E Class 100) laboratory should be used for the analysis of trace elements [51] and possible sources of contamination should be minimized or eliminated. For example, it was observed that chromium contamination increases tenfold when frozen muscle samples are cut by surgical blade 
as compared to fresh tissue cut by surgical blade [52]. Similarly, mills, grinders, and laboratory ware are common sources of trace element contamination. Extensive recommendations on prevention and remediation of laboratory contamination are given in [53].

Usefulness of elemental metabolomics will depend on large data sets where elemental profiles for a variety of samples are available and on ability to compare results from different studies. In addition to SOP, standard reference materials and reference materials are needed for comparability of results. Reference materials are homogeneous, stable and well-defined sources with known trace element concentrations. Well-characterized standard reference materials (SRM) and certified reference materials are critical for instrument to ensure the accuracy of measurements. There are three categories of assigned values of trace elements concentration in SRM (in declining order of confidence): certified values, reference values, and "for information" values [54]. Reference materials for trace elements exist but they rarely have values for more than 30 elements. Furthermore, SRM may consist of material that has very different concentration of elements than the target samples increasing the possibility of measurement error of low-concentration elements close to detection limits. For example, the SRM for lanthanides from mussel tissue (BCR-668) and aquatic plant tissue (BCR-670) have concentrations of individual lanthanides that can be 2-3 orders of magnitude higher than some target materials such as meat [55]. More details about SRM and complexities of establishing them can be found in [56]. Comprehensive metabolomics studies may include the screening of a variety of samples - from environment, soil, food, and human samples to track elements and their movement through the chain in order to study their effect on human health. Because of potentially large differences in concentration of certain elements multiple calibration standards need to be used to ensure that all elemental measurements will be within linear calibration ranges. To assure high accuracy of measurements, comprehensive sample-matched reference materials need to be developed and used. Environmental disasters and accidents may result in unpredictably elevated environmental exposure to a range of elements making standard reference materials unsuitable, even when multiple reference materials will be available. Standard analytical practices - dilution in combination with internal standards - are expected to be adequate in disaster and accidents monitoring.

Elemental metabolomics studies need to share minimum information reporting standards to enable comparability between studies and provide means to understand, evaluate, repeat, and re-investigate these studies. MIRS relevant to elemental metabolomics include those used in chemical analyses [15], and metabolomics experiments [57-59]. Based on these recommendations and our experience with elemental screening of concurrent measurement of large number of elements [17, 60], we have compiled a tentative MIRS for elemental metabolomics (Table 2). Examples of studies that have well-reported data can be found in [53, 61, 62]. For publications, it is recommended that the detailed reports, and individual sample measurements are provided as supplementary materials. These reporting standards transcend and unify all sub-fields of elemental metabolomics (ionomics, metalomics, minerallomics, and elementomics) [26-32]. 
Table 2. Tentative Minimal Information Reporting Standards (MIRS) for elemental metabolomics studies. More details are available from [15, 57-58]. Appropriate MIRS should be established and agreed by the professional communities and this MIRS framework represents an informed starting point. The concentration of elements is expressed as $w / w(\mu \mathrm{g} / \mathrm{kg})$ or $w / v(\mu \mathrm{g} / \mathrm{L})$ because they are widely used, wellunderstood, and are consistent with the International System of Units (SI) nomenclature and guidelines [63]. For sample description, European Food Safety Authority has provided a comprehensive set of guidelines [64].

\begin{tabular}{|c|c|}
\hline METADATA & REPORTING ITEMS \\
\hline Sampling process and protocol & $\begin{array}{l}\text { Replicate sampling and analysis } \\
\text { Tissue harvesting method } \\
\text { Biofluid harvesting and collection method } \\
\text { Tissue processing method (pre-analytic) } \\
\text { Storage conditions } \\
\text { Transport and shipping of samples } \\
\text { Methods for prevention of contamination }\end{array}$ \\
\hline $\begin{array}{l}\text { Sample preparation for elemental } \\
\text { analysis }\end{array}$ & $\begin{array}{l}\text { Chemicals and their descriptions } \\
\text { Internal standards, if any } \\
\text { Microwave oven program for digestion } \\
\text { Digestate handling/storage } \\
\text { Transport and shipping of digestates }\end{array}$ \\
\hline Sample preparation for speciation & $\begin{array}{l}\text { Chemicals/solvents and their description } \\
\text { Internal standards } \\
\text { Extracts handling/storage } \\
\text { Transport and shipping of extracts }\end{array}$ \\
\hline ICP-MS & $\begin{array}{l}\text { Instrument description } \\
\text { Sample introduction and delivery } \\
\text { lonization source } \\
\text { Mass analyzer description } \\
\text { Data acquisition parameters } \\
\text { Standard reference materials used } \\
\text { Targeted stable isotopes }\end{array}$ \\
\hline $\begin{array}{l}\text { Separation technique coupled to } \\
\text { ICP-MS for speciation }\end{array}$ & $\begin{array}{l}\text { Instrument description and setup } \\
\text { Interface to ICP-MS } \\
\text { Separation technique description }\end{array}$ \\
\hline Instrumental checks $\&$ performance & $\begin{array}{l}\text { Calibration and accuracy/precision assessment } \\
\text { Quality control samples } \\
\text { - replicates } \\
\text { - blanks } \\
\text { - } \text { spiked samples } \\
\text { - standard reference materials } \\
\text { Limits of detection (LOD) values } \\
\text { Limits of quantitation (LOQ) values } \\
\text { List of acceptance criteria }\end{array}$ \\
\hline
\end{tabular}

Table 2 continued on the next page 


\section{Data pre-processing}

Data reporting

\section{Biological experiment}

Data file format and conversion methods

Data pre-processing

- calibration curves

- background subtraction

- noise reduction

- interference correction measures

- dealing with LOD and LOQ

Elemental matrices and concentrations

- ranges, medians and averages

- reference intervals

Units (consistent with SI nomenclature [63])

- Use $\mu \mathrm{g} / \mathrm{kg}$ for solid, or $\mu \mathrm{g} / \mathrm{L}$ for liquid samples

- ppm (parts per million) and related terms (ppb, ppt) should not be used

- different scale units (such as $\mathrm{mg} / \mathrm{kg}$ and $\mu \mathrm{g} / \mathrm{kg}$ ) should not be used in the same report

- $\mathrm{mol} / \mathrm{kg}$ or $\mathrm{mol} / \mathrm{L}$ measures can be used if conversion factors to $\mu \mathrm{g} / \mathrm{kg}$ and $\mu \mathrm{g} / \mathrm{L}$ are provided

IUPAC nomenclature

Use recognized ontologies whenever possible

Sample description

- Organism, type, subtype, genotype

- Sample composition, sources

- Sample type (phenotype, weight, age, sex, characteristics, tissue)

- Other relevant details

Environment and conditions descriptions

- Control samples, disease/disorder, pollution, type of food taken, toxicity, occupational hazard, geographic location, time, production system, maintenance procedure and parameters, etc.

\section{Statistics and bioinformatics in elemental metabolomics}

Elemental matrices measured in biological samples are information-rich and show big variation of the values across different materials. Proper statistical and computational modelling techniques, ranging from descriptive statistics to the use of complex models, are essential for getting the value out of data.

Descriptive statistics is commonly used to provide an overview of elemental profiles. Descriptive statistics of elemental profiling studies provides meaningful summaries. Typical summaries 
report the number of samples, central tendency spread (minimum, maximum, average or median values, along with standard deviation and quantiles), and shape of the distributions (coefficients of skewness and kurtosis or histograms) [e.g. 65-67]. Descriptive statistics enables identification of simple patterns, and identification of dependencies in data sets. We can use descriptive univariate statistics for identification of outliers, possible associations, for example association between elemental levels in blood and mother's milk [66], and possible agonist and antagonist relations between individual elements [68]. Correlation tests are frequently used to test possible association between two variables. Linear correlation analysis identified pairs of elements that show strong positive correlation in human scalp hair samples and in fingernail samples, and also identified elements that showed strong positive correlation between their concentrations in hair and nail [69, 70]. Reference Value Advisor program [71] is very useful for univariate analysis of elemental matrices. It enables calculation of reference intervals along with their $90 \%$ confidence intervals, for each element. These values are calculated using appropriate statistics and transformations (non-parametric, parametric, and robust Box-Cox transformed methods) in accordance to international recommendations [72]. In addition, it tests the normality of distributions and displays $\mathrm{Q}-\mathrm{Q}$ plots, identifies possible outliers, and displays the distribution plots and histograms. Knowledge of reference values and their statistical properties allows comparison of results measured by different methods, or comparison of samples that represent different conditions and their variations.

Hypothesis testing is a common goal of exploratory data analysis such as univariate analysis and data agreement testing [73]. Selection of an appropriate method depends on the research questions and the types of data collected [74]. One of the most used test, analysis of variance (ANOVA), tests the differences of means between two or more groups. In [75] ANOVA was used to determine significant variation of $\mathrm{Cr}, \mathrm{Mn}, \mathrm{Sr}, \mathrm{Pb}$, and $\mathrm{V}$ between cow milk samples from different farms in South Africa. These results suggested that milk samples from different geographic regions may have different elemental compositions, thus having different nutritional profiles as well as different toxic content. More complex interactions, such as exposure to multiple elements and their dependencies can be studied using multiple regression. Regression analysis can generate a mathematical equation that can predict the dependent variable from values of independent variables. Linear regression analysis of elemental profiles in human hair revealed possible dependencies between groups of elements [70] - it indicated that the concentration of $\mathrm{Al}$ in hair can be expressed as a function of concentrations of $U, P$, and $M n$. The same study indicated strong interrelationships of industrially-related elements that contribute to environmental pollution in hair samples from exposed population. Synergistic and antagonistic relationships between elements have been observed - the combined effect, such as toxicity, of two elements is higher than individual effects when both elements are present (synergy), or combined effect might be lower than individual effects (antagonism) [76]. Non-linear multiple regression was used to study occupational hazard related to eight metals in welders [77]. This study showed that welders have higher concentration of metals in blood and urine, and that they also have higher rate of DNA damage than controls. Logistic regression model estimates the probability of categorical dependent variable using data from elemental matrices. In elemental metabolomics type of study, logistic regression was used to predict physiological status of plant from leaf elemental profile (5 elements) [78], to study possible associations of autism with hair 
concentration of trace elements (17 elements) [79], and to evaluate possible interactions in metal ions as risk factors for prostate cancer (4 elements) [80]. A major deficiency in majority of these studies is that most of them involved screening of relatively small number of elements as compared with $>70$ that are currently measurable by ICP-MS.

Exploratory analysis of high-dimensional data sets and hypothesis generation are supported by a variety of machine learning approaches that perform regression analysis, clustering, classification, and data visualizations. Methods that are commonly used for elemental data analysis are principal component analysis (PCA), linear discriminant analysis (LDA), classification and regression trees (CRT), k-means clustering, and hierarchical clustering with dendograms [60, 81]. PCA applies orthogonal transformation to a set of measurements to produce linearly uncorrelated variables or "principal components". PCA is commonly used for reduction of dimensionality of elemental profiles and is used in screening plant, food, and clinical samples [e.g. 82-84]. Hierarchical clustering partitions sets into groups of similar objects or "clusters" and builds a dendogram of the hierarchy of the clusters. This allows us to see how the samples group together based on similarity of elemental concentrations. It is widely used in study of food, water, and medical samples [85-87].

Predictive models including network models and decision trees have been explored in the study of elemental profiles in food science and health. For example, elemental analysis for identification of the island of origin of wine from Canary Islands showed that LDA and artificial neural networks (ANN) were highly accurate, with ANN outperforming LDA [88]. ANN, support vector machines (SVM) and decision trees were applied for classification of rice by geographic origin [89, 90]. Comparative analysis of ANN, SVM and decision tree classifiers were reported for classification of grape juice [91]. These studies are useful since they describe basic usage of advanced classification methods using elemental profiles, but need to be taken with caution since they were developed using small number of samples. With the number of reported samples growing and the increasing application of common standards across studies, the advanced classification methods will gain prominence. Elemental profiles combined with mutual information analysis were used to study associations between ion modules and networks with obesity, metabolic syndrome, and type 2 diabetes in Chinese adults [92]. The results were used to construct "disease-associated ion networks". A study of illicit drugs classification by origin using elemental profiles determined that PCA and hierarchical clustering were inadequate, while ANN-based classification showed $96-99 \%$ correct classification of ecstasy tablets by the law enforcement seizure [93]. Elemental profiling, thus can be used to trace illicit drugs to distribution networks, and ultimately to the origin of drugs. To build a predictive model from multidimensional data, it is often needed to reduce dimensionality by selection of critical variables and then use these variables to build classification models. In an investigation of chemical signatures (anionic, elemental, and isotopic profiles) of chemical threat agents, a comprehensive analysis was performed to enable tracing the source of cyanides [94]. Multiple approaches for selection of variables and for building classification models were assessed and compared. Dimensionality reduction was performed using hierarchical cluster analysis, PCA, Fisher-ratio from ANOVA, interval partial least squares (PLS) regression, and genetic algorithmbased PLS regression. Classification models in [94] were built using partial least squares 
discriminant, K-nearest neighbor clustering, and SVM. This study is interesting because it has demonstrated the use of several methods, showed how results may differ between methods, and showed how multiple methods can be combined for interpretation of results. We have summarized a selection of methods commonly used in elemental metabolomics in Table 3 .

Table 3. List of types of data analysis and a list of methods commonly used in elemental metabolomics studies. This list is not exhaustive but it is intended to provide a brief overview of statistical and mathematical tools that support elemental metabolomics data workflow shown in Figure 1. A comprehensive study involves types of analysis done sequentially: descriptive statistics $\rightarrow$ data cleaning $\rightarrow$ exploratory data analysis $\rightarrow$ predictive modeling. Each example of methods and tools may have multiple uses from the corresponding "Used for" group.

\section{Type of analysis Examples of methods and tools Used for}

\begin{tabular}{|c|c|c|}
\hline $\begin{array}{l}\text { Descriptive } \\
\text { statistics }\end{array}$ & $\begin{array}{l}\text { Plots, charts and histograms } \\
\text { Mean, median, range, quantiles } \\
\text { Variance and standard deviation } \\
\text { Skewness and kurtosis } \\
\text { Correlation and covariance }\end{array}$ & $\begin{array}{l}\text { Summarizing samples } \\
\text { Assessing central tendency and } \\
\text { dispersion } \\
\text { Assessing shapes of distribution } \\
\text { Measuring dependencies }\end{array}$ \\
\hline Data cleaning & $\begin{array}{l}\text { Clustering algorithms } \\
\text { Data imputation methods } \\
\text { Outlier detection } \\
\text { Filtering algorithms } \\
\text { Aggregation and normalization algorithms }\end{array}$ & $\begin{array}{l}\text { Data correction } \\
\text { Data preprocessing } \\
\text { Data harmonization } \\
\text { Data standardization } \\
\text { Combining or grouping data }\end{array}$ \\
\hline $\begin{array}{l}\text { Exploratory data } \\
\text { analysis }\end{array}$ & $\begin{array}{l}\text { Principal component analysis } \\
\text { Clustering methods } \\
\text { Regression methods } \\
\text { Partial least squares discriminant analysis } \\
\text { Classification and regression trees } \\
\text { Analysis of variance } \\
\text { Linear discriminant analysis } \\
\text { Visualization techniques }\end{array}$ & $\begin{array}{l}\text { Assessment of assumptions } \\
\text { Statistical inference } \\
\text { Dimensionality reduction } \\
\text { Feature selection and model selection } \\
\text { Formulating and testing hypotheses } \\
\text { Pattern recognition } \\
\text { Design of further analysis } \\
\text { Design of further experiments }\end{array}$ \\
\hline $\begin{array}{l}\text { Predictive } \\
\text { modeling and } \\
\text { simulation }\end{array}$ & $\begin{array}{l}\text { Regression models } \\
\text { Probabilistic models } \\
\text { Decision trees } \\
\text { Cluster analysis } \\
\text { Markov chains } \\
\text { Neural networks } \\
\text { Support vector machines } \\
\text { Hybrid models } \\
\text { Ensemble models }\end{array}$ & $\begin{array}{l}\text { Statistical inference } \\
\text { Pattern recognition } \\
\text { Classification and prediction } \\
\text { Survival analysis } \\
\text { Decision making } \\
\text { Data mining } \\
\text { Big Data analytics }\end{array}$ \\
\hline
\end{tabular}


Complex elemental interactions are often difficult to analyze and interpret. The interpretation of these results needs to be taken with caution because causal relationship cannot be inferred from these results. Causation can be inferred in a randomized study that takes into account multiple factors that could be associated. For elemental studies of human samples these factors include, among others, diet, nutritional supplementation, lifestyle, environmental and occupational exposure, age, sex, genetic predisposition, use of cosmetics, and medication. This makes human studies much more complex than studies with laboratory animals, farm animals, or plants where many of the factors can be controlled.

\section{Conclusion and discussion}

Important applications of elemental metabolomics used for biomonitoring are emerging in environmental science, agriculture, food science, nutrition, pharmacology, and medicine [95]. ICP-MS combined with microwave digestion has been validated for simultaneous determination of multiple elements in various foodstuffs [96-98] including crops [99, 100], livestock [62, 101], and fish [102]. Important applications include food quality control [103], food authentication [17], and food safety and control [104].

ICP-MS is suitable for biomonitoring of human samples including blood, urine, and hair [105-107]. ICP-MS is used in environmental research [108], infant and adult nutrition [66, 109, 110], as well as the analysis of drugs and pharmaceuticals, medicinal plants and supplements [95]. Furthermore, ICP-MS based multi-elemental monitoring has applications in medicine including toxicology [111], occupational health [76], and is being developed for clinical diagnostics and monitoring $[112,113]$. Currently, there are more than 40 clinical laboratory blood tests for individual elements in human blood and other fluids and most of them use ICP-MS. These tests are performed individually for each element. Multi-element clinical laboratory testing offers an enormous opportunity for the improvement of diagnostics as it will enable understanding of elemental interactions, and more detailed understanding of the exposure patterns to elements and their combinations.

It was shown that large number of elements can be screened simultaneously, for example 60 elements were screened for their concentration in human blood [114]. However, only in the last few years we acquired the ability to make these screenings sufficiently accurate and cheap for routine use in wide range of applications. Development of tests for simultaneous multi-element screening will require improved SRMs, well-defined reference values, databases that store values of elemental profiles representative of conditions of interest, and specialized computational algorithms for data comparison and analysis. New SRMs that can be used for screening of more than 70 elements are needed. For specific applications, SRMs should have elemental concentration ranges similar to the concentration ranges in target samples - to ensure good matching of linear ranges of measurements. They should ideally be derived from materials similar to target samples. Elemental reference values - concentrations of elements expected to be found 
in control populations - have been proposed $[105,115]$. These reference values are crude since they were done on small sample and do not provide detailed description of target population (by age, geographic origin, occupation, etc.). There is a need for systematic screening of population for establishing baseline values that take into account various confounding variables. The interpretation of elemental profile measurements requires comparison with data from reference databases of elemental profiles that represent a broad variety of biological samples and various conditions and geographic origins. Such databases have been proposed in various meetings, but to our knowledge they either do not exist or they are not publicly available. Along with the emergence of these databases, analysis tools for comparison of samples and analysis will be developed. The main obstacles for advancing the field of elemental metabolomics are the incomplete screening and small number of samples that are used in today's typical studies.

Recent technological advancements in mass spectrometry including triple-quadrupole ICP-MS configurations offer unprecedented measurement capabilities and increased productivity. Improvements that are available within several configurations include increased matrix tolerance and reduced measurement drift due to clogging, higher sensitivity, improved measurement for problematic analytes such as S or Si, and dynamic range of up to 11 orders of magnitude [116]. Laser ablation coupled ICP-MS (LA-ICP-MS) enables screening of tiny samples such as nanoparticles, single cells, or single strands of hair as well as variation in distribution of elements within the sample on a nanometer scale $[100,117]$ opening possibilities for the development of new diagnostic methods. Current technologies demonstrated the ability for profiling of ${ }^{13} \mathrm{C},{ }^{23} \mathrm{Na}$, ${ }^{24} \mathrm{Mg},{ }^{31} \mathrm{P},{ }^{39} \mathrm{~K},{ }^{56} \mathrm{Fe},{ }^{63} \mathrm{Cu},{ }^{65} \mathrm{Cu}$, and ${ }^{64} \mathrm{Zn}$ from a single cell from cultured neurons [120]. Although ICP-MS is a destructive method, the minute quantities of sample can be used, thus enabling needle biopsies, colonoscopy, hair analysis and other minimally invasive methods to be deployed. The analysis of a hair using LA-ICP-MS has demonstrated that exposure change due to nutrition [119] or geographic relocation [117] can be reproducibly measured. Such unprecedented ability for accurate measurement of elements from tiny samples will enable comprehensive analysis of elemental profiles including elements that are present in ultra-low concentrations. Many potential applications are emerging because we can monitor trace element homeostasis using systems approach rather than traditional single-element analysis [121,122]. Understanding of multi-element homeostasis is necessary for understanding the mechanistic basis of toxicity due to chronic exposure, related cell and organ toxicity, and related health consequences. Elemental toxicity is complex and may be due to increased intake (environmental, occupational, nutritional, medicinal), increased permeability (e.g. gut, dermal, or vascular), excretory deficiency (e.g. organ damage, genetic impairments), malnutrition, or chronic homeostatic imbalances of elements such as $\mathrm{Ca}, \mathrm{Cu}, \mathrm{Fe}$, and $\mathrm{Zn} \mathrm{[123-126].} \mathrm{Chronic} \mathrm{toxicity,} \mathrm{therefore,} \mathrm{is} \mathrm{a} \mathrm{multifactorial} \mathrm{process} \mathrm{and}$ its study involves complex systems analysis. Elemental metabolomics involves the study of bioavailability and transfer of elements between the environment, food chain, and various subsystems of plant, animal and human organisms. Highly accurate profiling of trace and ultratrace elements enables insight into elemental homeostasis and combine it with genomic, proteomic, and metabolomics analysis of tissues and cell types. More than 20 elements are considered as toxic risk ( $\mathrm{Ag}, \mathrm{As}, \mathrm{Au}, \mathrm{Be}, \mathrm{Bi}, \mathrm{Cd}, \mathrm{Ce}, \mathrm{Ch}, \mathrm{Co}, \mathrm{Cu}, \mathrm{Fe}, \mathrm{Ga}, \mathrm{Hg}, \mathrm{Mn}, \mathrm{Ni}, \mathrm{Pb}, \mathrm{Pt}, \mathrm{Sb}, \mathrm{Sn}$, $\mathrm{Te}, \mathrm{Th}, \mathrm{U}, \mathrm{V}$, and $\mathrm{Zn}$ ) and seven of them are considered as high-risk ( $\mathrm{As}, \mathrm{Al}, \mathrm{Cd}, \mathrm{Cr}, \mathrm{Fe}, \mathrm{Hg}$, and $\mathrm{Pb}$ ) [128]. Neurotoxicity of $\mathrm{As}, \mathrm{Cd}, \mathrm{Cu}, \mathrm{Fe}, \mathrm{Hg}, \mathrm{Mn}, \mathrm{Pb}$, and $\mathrm{Zn}$ has been well-known but the toxic dose 
was difficult to establish because co-exposure to multiple metals can result in toxicity at individually sub-toxic doses [129]. New methods for establishing toxicity are needed and we anticipate that multi-element signatures that correspond to toxicity will be defined through use of elemental metabolomics and appropriate statistical modeling. The ability to concurrently measure bioavailability of elements from environment, food, and various tissues enables elemental metabolomics to be a comprehensive medical diagnostic tool [125] and provides basis for design of medical and nutritional intervention. For example, elemental metabolomics can be used to decipher the mystery of neurotoxic damage, such as in autism spectrum disorder, by combining elemental screening of biological samples at multiple times during pregnancy, infancy and early development. Exposure to toxic metals and homeostatic perturbations are associated with autism either through mother exposure during pregnancy, or exposure during early development [126,128-130]. Known gestational exposures associated to autism include As, Cd, $\mathrm{Hg}$, and $\mathrm{Pb}$ and possibly $\mathrm{Al}, \mathrm{Cr}, \mathrm{F}, \mathrm{Mn}, \mathrm{Ni}, \mathrm{Sn}$, and $\mathrm{U}$ [130]. Increased exposure to heavy metals was reported to be higher in infants (0-3 years of age) then in older children [128]. Furthermore, $\mathrm{Mg}$ and $\mathrm{Zn}$ deficiency and lower levels of $\mathrm{Ca}, \mathrm{Fe}, \mathrm{Mn}$ and Se and increased level of $\mathrm{Cu}$ and other toxic metals have been observed, and these differences have been more pronounced in autistic children then in controls [121,126,128-130]. Elemental metabolomics enables screening of environmental, nutritional, and medical (blood, hair, nails) samples where comprehensive elemental signatures that confer high or low risk of autism can be identified and stored in databases. These signatures promise to be better risk and exposure biomarkers than individual elements/toxins because effects of toxic chemicals are often synergistic and cumulative [131]. Biomonitoring of complete elemental profiles can provide early risk assessment and diagnosis and subsequently support early intervention (Figure 3).

ICP-MS alone can measure only the total concentration of each element and their isotopes in the sample. This information alone is often insufficient for understanding the inorganic metabolome effects. For example, the risk of toxicity of trace metals such as arsenic, mercury, chromium or selenium is dependent on bioavailability related to elemental species [39,131]. Multiple inorganic and organic forms are available for these metals and they differ in toxicity, absorption, and concentration in different biological samples. Basic elemental metabolomics represent an important baseline and can determine overall subtoxic levels of these elements. Separation techniques [38] are often coupled with ICP-MS; they discriminate different species of elements and provide for deep insight about the concentration of each species. Elemental metabolomics combined with speciation analysis provide a link between inorganic and organic metabolites and detailed profiling of toxic element compounds in both elemental and organic form. We estimate that speciation analysis will introduce additional 50-100 inorganic species and 200-300 organic species of interest to a complete complement of elemental metabolomics targets. Continuous improvement of analytical capabilities and detection limits will see the increase of these numbers. Elemental metabolomics focuses on comprehensive measurement of total elemental concentrations and is, by its nature, targeted screening. Speciation analysis provides finer granularity of targeted screening by providing concentrations of elemental species. Furthermore, speciation analysis provides a link between inorganic and organic metabolites since large number of organic metabolites can be measured directly as elemental species after the separation step. 


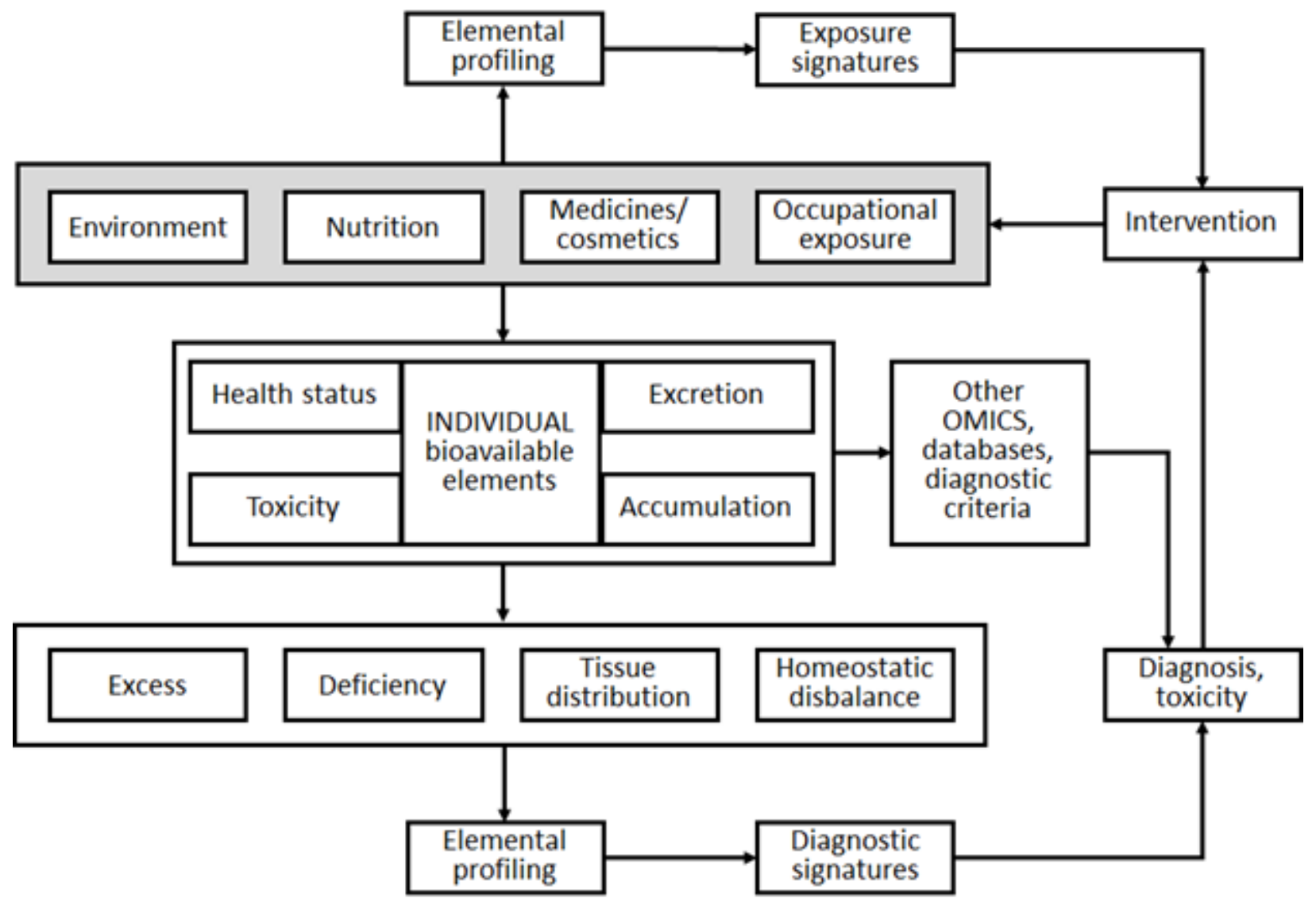

Figure 3. A model of elemental metabolomics screening of external (environment, nutrition, medicine/cosmetics and occupational) and internal (excess, deficiency, tissue distribution, and homeostatic disbalance) factors. Elemental profiling provides of exposure signatures and diagnostic signatures for estimation of toxicity, diagnosis, and design of intervention - nutritional, medical, or preventative. Resistance to toxicity can be studied by the analysis of genetic variants of susceptibility or protection specific for an individual or considering antagonism or synergy of elements. This model is suitable for the study of complex disorders such as autism and other disorders such as metabolic disorders or organ damage. A convenient starting point of this model is the measurement of external factors, indicated as the shaded box.

We foresee a significant growth of the field of elemental metabolomics since it connects multiple fields that affect quality of life, health and the economy. The new development will include creation of several types of databases of comprehensive elemental profiles for plants, animals, human and environment. These databases will focus on physiology, food and nutrition, and health. They will be populated from large-scale projects that will generate tens of thousands of individual fingerprints. These fingerprints will be used to define elemental signatures that will characterize origin of samples and that will be characteristic of various functional states. 
Comparison of new samples with the elemental signatures will enable characterization of these samples. These databases will be combined with advanced data analytical tools that will inform traditional metabolomics studies about total content and the distributions of elements in the samples. They will also enable investigations such as distinguishing various disease and healthy states, origin of food and detection of adulteration, enhancement of proteomics and genomics studies. The applications of elemental metabolomics will be numerous, examples including the design of new diagnostic and prognostic tools for health, improved occupational health, improvements of agricultural practices and quality of food, and better protection of environment.

Multi-element analysis by ICP-MS is increasingly being used in biotechnology because of ultrahigh sensitivity and selectivity, high-throughput multi-element measuring capability, accurate absolute quantification in complex matrices, easy combination with chromatographic separation methods, its complementarity with organic mass spectrometry, and isotope measuring ability [132]. About $30 \%$ of proteins in human body are metalloproteins. Clinical testing often involves quantification of specific proteins that serve as disease markers, but reliable, reproducible and traceable measurements are currently lacking. Metrology of metalloproteins recognized ICP-MS elemental measurement combined with separation techniques as a valid methodology with traceability due to availability of SRMs [133]. Metalloproteins provide a direct link between elemental metabolomics and proteomics and we expect that increasing number of metabolite measurements will be done by direct measurement of elements. Furthermore, increasing number of specialized multielement clinical testing have been validated $[134,135]$ and ICP-MS is used routinely for large number of laboratory tests for total elements in biological samples (Ag, Al, As, Ba, Be, Bi, Cd, Cr, Co, Cu, Fe, Gd, Hg, I, Mg, Mn, Mo, Ni, Pb, Pt, Se, Sb, Sn, Th, Ti, U, V, Zn), including several metal panels, in reputable clinical laboratories [136].

Elemental metabolomics offers possibilities of improving our understanding of environment, nutrition and health. Elemental metabolomics will inform traditional metabolomics through reduction of complexity of metabolic experiments, better design of metabolomics studies and improved ability for interpretation of results. Ultimately, elemental metabolomics will enable better understanding of biological functioning of organisms and the role of environmental influences, nutrition, and chronic exposure to various elements.

\section{References}

1. Williams RJ, Berry $\amalg$, Beerstecher Jr E. Individual metabolic patterns, alcoholism, genetotrophic diseases. Proc Natl Acad Sci USA 1949;35(6):265. DOI: 10.1073/pnas.35.6.265

2. Thompson JA, Markey SP. Quantitative metabolic profiling of urinary organic acids by gas chromatography-mass spectrometry: comparison of isolation methods. Anal Chem 1975;47(8):1313-21. DOI: 10.1021/ac60358a074 
3. Maurer HH. Screening procedures for simultaneous detection of several drug classes used for high throughput toxicological analyses and doping control. A review. Comb Chem High Throughput Screening. 2000;3(6):467-80. DOI: http://dx.doi.org/10.2174/1386207003331355

4. Gibon $Y$, Vigeolas $H$, Tiessen A, Geigenberger $P$, Stitt $M$. Sensitive and high throughput metabolite assays for inorganic pyrophosphate, ADPGlc, nucleotide phosphates, and glycolytic intermediates based on a novel enzymic cycling system. Plant J 2002;30(2):221-35. DOI: 10.1046/j.1365-313X.2001.01278.x

5. Goodacre R, Vaidyanathan S, Dunn WB, et al. Metabolomics by numbers: acquiring and understanding global metabolite data. Trends Biotechnol 2004;22(5):245-52.1 DOI: 10.1016/j.tibtech.2004.03.007

6. Fiehn O. Metabolomics-the link between genotypes and phenotypes. Plant Mol Biol 2002;48(1-2):155-71. DOI: 10.1023/A:1013713905833

7. Beecher CW. The human metabolome. In Harrigan GG, Goodacre Royston (eds). Metabolic profiling: Its role in biomarker discovery and gene function analysis. New York: Springer Science+Business Media 2003, 311-19.

8. Milne GL, Morrow JD. Measurement of biological materials. In: Robertson D, Williams GH, (eds). Clinical and Translational Science: Principles of Human Research. Academic Press, 2009, 69-86.

9. Bujak R, Struck-Lewicka W, Markuszewski MJ, et al. Metabolomics for laboratory diagnostics. J Pharm Biomed Anal 2015;113:108-20. DOI: 10.1016/j.jpba.2014.12.017

10. Brown M, Dunn WB, Ellis DI, et al. A metabolome pipeline: from concept to data to knowledge. Metabolomics 2005;1(1):39-51. DOI: 10.1007/s11306-005-1106-4

11. Broadhurst DI, Kell DB. Statistical strategies for avoiding false discoveries in metabolomics and related experiments. Metabolomics 2006;2:171-96. DOI: 10.1007/s11306-006-0037-z

12. Bernini P, Bertini I, Luchinat $C$, et al. Standard operating procedures for pre-analytical handling of blood and urine for metabolomic studies and biobanks. J Biomol NMR 2011;49(34):231-43.

13. Yin $P$, Lehmann $R, X u$ G. Effects of pre-analytical processes on blood samples used in metabolomics studies. Anal Bioanal Chem 2015;407(17):4879-92.

14. Lobinski R, Moulin C, Ortega R. Imaging and speciation of trace elements in biological environment. Biochimie 2006;88(11):1591-604. DOI: 10.1016/j.biochi.2006.10.003

15. Sumner LW, Amberg A, Barrett D, et al. Proposed minimum reporting standards for chemical analysis. Metabolomics 2007;3(3):211-21. DOI: 10.1007/s11306-007-0082-2

16. Geffré A, Friedrichs K, Harr K, et al. Reference values: a review. Vet Clin Pathol 2009;38(3):288-98. DOI: 10.1111/j.1939-165X.2009.00179.x

17. Danezis GP, Tsagkaris AS, Brusic V, et al. Food authentication: state of the art and prospects. Curr Opin Food Sci 2016;10:22-31. DOI: 10.1016/j.cofs.2016.07.003

18. Zamboni N, Saghatelian A, Patti GJ. Defining the metabolome: size, flux, and regulation. Mol Cell 2015;58(4):699-706. DOI: 10.1016/j.molcel.2015.04.021

19. Wishart DS, Jewison T, Guo AC, et al. HMDB 3.0-the human metabolome database in 2013. Nucleic Acids Res 2012:D801-7. DOI: 10.1093/nar/gks1065

20. Fuhrer T, Zamboni N. High-throughput discovery metabolomics. Curr Opin Biotechnol 2015;31:73-8. DOI: 10.1016/j.copbio.2014.08.006 
21. Rubingh CM, Bijlsma S, Derks EP, et al. Assessing the performance of statistical validation tools for megavariate metabolomics data. Metabolomics 2006;2(2):53-61. DOI: 10.1007/s11306-006-0022-6

22. Emsley J. The Elements. Oxford: Clarendon Press, 1998.

23. ICP Mass Spectrometry. The 30-Minute Guide to ICP-MS. Technical Note, Perkin-Elmer Instruments, 2001.

24. Thomas R. Practical guide to ICP-MS: a tutorial for beginners. New York: Marcel Dekker, 2013.

25. Pröfrock D, Prange A. Inductively Coupled Plasma-Mass Spectrometry (ICP-MS) for quantitative analysis in environmental and life sciences: a review of challenges, solutions, and trends. Appl Spectrosc 2012;66(8):843-68. DOI: 10.1366/12-06681

26. Salt DE, Baxter I, Lahner B. Ionomics and the study of the plant ionome. Annu Rev Plant Biol 2008;59:709-33.

27. Eide DJ, Clark S, Nair TM, et al. Characterization of the yeast ionome: a genome-wide analysis of nutrient mineral and trace element homeostasis in Saccharomyces cerevisiae. Genome Biol 2005;6(9):1. DOI: 10.1186/gb-2005-6-9-r77

28. Matyssek R, Schnyder H, Oßwald W, et al. Growth and defence in plants. Berlin: Springer, 2014.

29. Harrington JM, Young DJ, Essader AS, et al. Analysis of human serum and whole blood for mineral content by ICP-MS and ICP-OES: development of a mineralomics method. Biol Trace Elem Res 2014;160(1):132-42. DOI: 10.1007/s12011-014-0033-5

30. Szpunar J. Metallomics: a new frontier in analytical chemistry. Anal Bioanal Chem 2004;378(1):54-6. DOI: 10.1007/s00216-003-2333-z

31. Łobiński R, Becker JS, Haraguchi H, et al. Metallomics: Guidelines for terminology and critical evaluation of analytical chemistry approaches (IUPAC Technical Report). Pure Appl Chem 2010;82(2):493-504. DOI: 10.1351/PAC-REP-09-03-04

32. Li YF, Chen C, Qu Y, et al. Metallomics, elementomics, and analytical techniques. Pure Appl Chem 2008;80(12):2577-94. DOI: 10.1351/pac200880122577

33. Ehlken S, Kirchner G. Environmental processes affecting plant root uptake of radioactive trace elements and variability of transfer factor data: a review. J Environ Radioact 2002;58(2):97-112.

34. Breton J, Daniel C, Dewulf J, et al. Gut microbiota limits heavy metals burden caused by chronic oral exposure. Toxicol Lett 2013;222(2):132-8. DOI: 10.1016/j.toxlet.2013.07.021

35. Taylor GJ. Multiple metal stress in Triticum aestivum. Differentiation between additive, multiplicative, antagonistic, and synergistic effects. Can J Bot 1989;67(8):2272-6.

36. Dudev T, Lim C. Competition among metal ions for protein binding sites: determinants of metal ion selectivity in proteins. Chem Rev 2013;114(1):538-56. DOI: 10.1021/cr4004665

37. Kawanishi S, Hiraku Y, Murata M, et al. The role of metals in site-specific DNA damage with reference to carcinogenesis. Free Radic Biol Med 2002;32(9):822-32.

38. Łobiński R, Szpunar J. Biochemical speciation analysis by hyphenated techniques. Anal Chim Acta 1999;400(1):321-32. DOI: 10.1016/S0003-2670(99)00628-5

39. Stohs SJ, Bagchi D. Oxidative mechanisms in the toxicity of metal ions. Free Radic Biol Med 1995;18(2):321-36. DOI:10.1016/0891-5849(94)00159-H

40. Harada M. Minamata disease: methylmercury poisoning in Japan caused by environmental pollution. Crit Rev Toxicol 1995;25(1):1-24. DOI: 10.3109/10408449509089885

41. Zhang $H$, Feng $X$, Larssen $T$, et al. In inland China, rice, rather than fish, is the major pathway for methylmercury exposure. Environ Health Perspect 2010;118(9):1183. DOI: 10.1289/ehp.1001915 
42. Gannes LZ, Del Rio CM, Koch P. Natural abundance variations in stable isotopes and their potential uses in animal physiological ecology. Comp Biochem Physiol A Mol Integr Physiol 1998;119:725-37.

43. Anbar $A D$, Rouxel $O$. Metal stable isotopes in paleoceanography. Annu Rev Earth Planet Sci 2007;35:717-46. DOI: 10.1146/annurev.earth.34.031405.125029

44. Kind $\mathrm{T}$, Fiehn $\mathrm{O}$. Metabolomic database annotations via query of elemental compositions: mass accuracy is insufficient even at less than 1 ppm. BMC bioinformatics 2006;7(1):1. DOI: 10.1186/14712105-7-234

45. Schmidt O, Quilter JM, Bahar B, et al. Inferring the origin and dietary history of beef from C, N and S stable isotope ratio analysis. Food Chem 2005;91(3):545-9. DOI: 10.1016/j.foodchem.2004.08.036

46. Emons H. Sampling: collection, storage, Chapter 2. In Cornelis R, Caruso J, Crews H, et al. (eds). Handbook of Elemental Speciation: Techniques and Methodology. Chichester: Wiley 2003; 7-22. DOI: 10.1002/0470868384

47. Committee for Medicinal Products for Human Use. Guideline on bioanalytical method validation. London: European Medicines Agency, 2011.

48. Ruggieri F, Alimonti A, Bocca B. Full validation and accreditation of a method to support human biomonitoring studies for trace and ultra-trace elements. TrAC Trends Anal Chem 2016;80:471-85. DOI: 10.1016/j.trac.2016.03.023

49. Vaught JB. Blood collection, shipment, processing, and storage. Cancer Epidemiol Biomarkers Prev 2006;15(9):1582-4.

50. Elemental Analysis Manual (EAM) for Food and Related Products. US Food and Drug Administration. http://www.fda.gov/Food/FoodScienceResearch/LaboratoryMethods/ucm2006954.htm (12 Sep. 2016, date last accessed)

51. Capar SG, Mindak WR, Cheng J. Analysis of food for toxic elements. Anal Bioanal Chem 2007;389(1):159-69. DOI: 10.1007/s00216-007-1433-6

52. De Cremer K. Sampling of clinical samples: collection and storage. In Cornelis R, Caruso J, Crews H, et al. Handbook of Elemental Speciation: Techniques and Methodology. Chichester: Wiley 2003; 23-46. DOI: 10.1002/0470868384

53. Rodushkin I, Engström E, Baxter DC. Sources of contamination and remedial strategies in the multielemental trace analysis laboratory. Anal Bioanal Chem 2010;396(1):365-77. DOI: 10.1007/s00216009-3087-z

54. Sharpless KE, Thomas JB, Christopher SJ, et al. Standard reference materials for dietary supplement analysis. Anal Bioanal Chem 2007;389(1):171-8. DOI: 10.1007/s00216-007-1315-y

55. Kramer KJ, de Haan EP, van het Groenewoud $\mathrm{H}$, et al. Certified reference materials for the quality control of rare earth element determinations in the environment. TrAC Trends Anal Chem 2002;21(11):762-73. DOI: 10.1016/S0165-9936(02)01101-9

56. Choi SJ, Lee KJ, Yoh JJ. Quantitative laser-induced breakdown spectroscopy of standard reference materials of various categories. Appl Phys B 2013;113(3):379-88. DOI: 10.1007/s00340-013-5474-6

57. Bino RJ, Hall RD, Fiehn O, et al. Potential of metabolomics as a functional genomics tool. Trends Plant Sci 2004;9(9):418-25. DOI: 10.1016/j.tplants.2004.07.004

58. Morrison N, Bearden D, Bundy JG, et al. Standard reporting requirements for biological samples in metabolomics experiments: environmental context. Metabolomics 2007;3(3):203-10. DOI: 10.1007/s11306-007-0080-4

59. Griffin JL, Nicholls AW, Daykin CA, et al. Standard reporting requirements for biological samples in metabolomics experiments: mammalian/in vivo experiments. Metabolomics 2007;3(3):179-88. DOI: 10.1007/s11306-007-0080-4

60. Drivelos SA, Georgiou CA. Multi-element and multi-isotope-ratio analysis to determine the geographical origin of foods in the European Union. TrAC Trends Anal Chem 2012;40:38-51. DOI: 10.1016/j.trac.2012.08.003 
61. Pinson SR, Tarpley L, Yan W, et al. Worldwide genetic diversity for mineral element concentrations in rice grain. Crop Sci 2015;55(1):294-311. DOI: 10.2135/cropsci2013.10.0656

62. Giannenas I, Nisianakis P, Gavriil A, et al. Trace mineral content of conventional, organic and courtyard eggs analysed by inductively coupled plasma mass spectrometry (ICP-MS). Food Chem 2009;114(2):706-11. DOI: 10.1016/j.foodchem.2008.09.079

63. Taylor BN, Thompson A. Guide for the Use of the International System of Units (SI). NIST Special Publication 811. National Institute of Standards and Technology, 2008.

64. EFSA (European Food Safety Authority). Standard sample description version 2.0. EFSA J 2013;11(10):3424. DOI: 10.2903/j.efsa.2013.3424

65. Wang Y, Ou YL, Liu YQ, et al. Correlations of trace element levels in the diet, blood, urine, and feces in the Chinese male. Biol Trace Elem Res 2012;145(2):127-35. DOI: 10.1007/s12011-011-9177-8

66. Almeida AA, Lopes CM, Silva AM, et al. Trace elements in human milk: correlation with blood levels, inter-element correlations and changes in concentration during the first month of lactation. J Trace Elem Med Biol 2008;22(3):196-205. DOI: 10.1016/j.jtemb.2008.03.007

67. Stalder $\mathrm{E}$, Blanc $\mathrm{A}$, Haldimann $\mathrm{M}$, et al. Occurrence of uranium in Swiss drinking water. Chemosphere 2012;86(6):672-9. DOI: 10.1016/j.chemosphere.2011.11.022

68. Vrček V, Vinković Vrček I. Metals in organic and conventional wheat flours determined by an optimised and validated ICP-MS method. Int J Food Sci Technol 2012;47(8):1777-83. DOI: 10.1111/j.1365-2621.2012.03034.x

69. Rodushkin I, Axelsson MD. Application of double focusing sector field ICP-MS for multielemental characterization of human hair and nails. Part I. Analytical methodology. Sci Total Environ 2000;250(1):83-100. DOI: 10.1016/S0048-9697(00)00369-7

70. Chojnacka K, Górecka H, Chojnacki A, et al. Inter-element interactions in human hair. Environ Toxicol Pharmacol 2005;20(2):368-74. DOI: 10.1016/j.etap.2005.03.004

71. Geffré A, Concordet D, Braun JP, et al. Reference Value Advisor: a new freeware set of macroinstructions to calculate reference intervals with Microsoft Excel. Vet Clin Pathol 2011;40(1):107-12. DOI: 10.1111/j.1939-165X.2011.00287.x

72. CLSI. Defining, Establishing, and Verifying Reference Intervals in the Clinical Laboratory; Approved Guideline. $3^{\text {rd }}$ ed. Wayne, PA: CLSI, 2008.

73. Jakobsson $U$, Westergren A. Statistical methods for assessing agreement for ordinal data. Scand J Caring Sci 2005;19(4):427-31. DOI: 10.1111/j.1471-6712.2005.00368.x

74. Nayak B, Hazra A. How to choose the right statistical test? Indian J Ophthalmol 2011; 59(2): 85-86. DOI: 10.4103/0301-4738.77005

75. Ataro A, McCrindle RI, Botha BM, et al. Quantification of trace elements in raw cow's milk by inductively coupled plasma mass spectrometry (ICP-MS). Food Chem 2008;111(1):243-8. DOI: 10.1016/j.foodchem.2008.03.056

76. Apostoli P. Elements in environmental and occupational medicine. J Chromatogr B Analyt Technol Biomed Life Sci 2002;778(1):63-97.

77. Iarmarcovai G, Sari-Minodier I, Chaspoul F, et al. Risk assessment of welders using analysis of eight metals by ICP-MS in blood and urine and DNA damage evaluation by the comet and micronucleus assays; influence of XRCC1 and XRCC3 polymorphisms. Mutagenesis 2005;20(6):425-32. DOI: 10.1093/mutage/gei058

78. Baxter IR, Vitek $\mathrm{O}$, Lahner $\mathrm{B}$, et al. The leaf ionome as a multivariable system to detect a plant's physiological status. Proc Natl Acad Sci USA 2008;105(33):12081-6. DOI: 10.1073/pnas.0804175105

79. De Palma G, Catalani S, Franco A, et al. Lack of correlation between metallic elements analyzed in hair by ICP-MS and autism. J Autism Dev Disorders 2012;42(3):342-53. DOI: 10.1007/s10803-011$1245-6$ 
80. Sarafanov AG, Todorov TI, Centeno JA, et al. Prostate cancer outcome and tissue levels of metal ions. Prostate 2011;71(11):1231-8. DOI: 10.1002/pros.21339

81. Chudzinska M, Baralkiewicz D. Application of ICP-MS method of determination of 15 elements in honey with chemometric approach for the verification of their authenticity. Food Chem Toxicol 2011;49(11):2741-9. DOI: 10.1016/j.fct.2011.08.014

82. Tokalıoğlu Ş. Determination of trace elements in commonly consumed medicinal herbs by ICP-MS and multivariate analysis. Food Chem 2012;134(4):2504-8. DOI: 10.1016/j.foodchem.2012.04.093

83. Kelly S, Heaton K, Hoogewerff J. Tracing the geographical origin of food: The application of multielement and multi-isotope analysis. Trends Food Sci. Technol 2005;16(12):555-67. DOI: 10.1016/j.tifs.2005.08.008

84. Lavilla I, Costas M, San Miguel P, et al. Elemental fingerprinting of tumorous and adjacent nontumorous tissues from patients with colorectal cancer using ICP-MS, ICP-OES and chemometric analysis. Biometals 2009;22(6):863-75. DOI: 10.1007/s10534-009-9231-6

85. Bong YS, Shin WJ, Gautam MK et al. Determining the geographical origin of Chinese cabbages using multielement composition and strontium isotope ratio analyses. Food Chem 2012;135(4):2666-74. DOI: 10.1016/j.foodchem.2012.07.045

86. Chen K, Jiao JJ, Huang J, et al. Multivariate statistical evaluation of trace elements in groundwater in a coastal area in Shenzhen, China. Environ Pollut 2007;147(3):771-80. DOI: 10.1016/j.envpol.2006.09.002

87. Guzikowski W, Szynkowska MI, Motak-Pochrzęst H, et al. Trace elements in seminal plasma of men from infertile couples. Arch Med Sci 2015;11(3):591-8. DOI: 10.5114/aoms.2015.52363

88. Pérez-Trujillo JP, Barbaste $M$, Medina B. Chemometric study of bottled wines with denomination of origin from the Canary Islands (Spain) based on ultra-trace elemental content determined by ICP-MS. Anal Lett 2003;36(3):679-97. DOI: 10.1081/AL-120018257

89. Marini F, Zupan J, Magrì AL. On the use of counterpropagation artificial neural networks to characterize Italian rice varieties. Anal Chim Acta 2004;510(2):231-40. DOI: 10.1016/j.aca.2004.01.009

90. Maione C, Batista BL, Campiglia AD, et al. Classification of geographic origin of rice by data mining and inductively coupled plasma mass spectrometry. Comput Electron Agric 2016;121:101-7. DOI: 10.1016/j.compag.2015.11.009

91. Maione C, de Paula ES, Gallimberti M, et al. Comparative study of data mining techniques for the authentication of organic grape juice based on ICP-MS analysis. Expert Syst App/ 2016;49:60-73. DOI: 10.1016/j.eswa.2015.11.024

92. Sun $L, Y u Y$, Huang $T$, et al. Associations between ionomic profile and metabolic abnormalities in human population. PLoS One. 2012;7(6):e38845. DOI: 10.1371/journal.pone.0038845

93. Waddell RJ, NicDaéid N, Littlejohn D. Classification of ecstasy tablets using trace metal analysis with the application of chemometric procedures and artificial neural network algorithms. Analyst 2004;129(3):235-40. DOI: 10.1039/B312336G

94. Mirjankar NS, Fraga CG, Carman AJ, et al. Source attribution of cyanides using anionic impurity profiling, stable isotope ratios, trace elemental analysis and chemometrics. Anal Chem 2016; 88(3):1827-34. DOI: 10.1021/acs.analchem.5b04126

95. Taylor A, Branch S, Day MP, et al. Atomic spectrometry update. Clinical and biological materials, foods and beverages. J Anal At Spectrom 2006;21(4):439-91. DOI: 10.1039/C3JA90005C

96. Millour S, Noël L, Kadar A, et al. Simultaneous analysis of 21 elements in foodstuffs by ICP-MS after closed-vessel microwave digestion: Method validation. J Food Comp Anal 2011;24(1):111-20. DOI: 10.1016/j.jfca.2010.04.002 
97. Chevallier E, Chekri R, Zinck J, et al. Simultaneous determination of 31 elements in foodstuffs by ICPMS after closed-vessel microwave digestion: method validation based on the accuracy profile. $J$ Food Comp Anal 2015;41:35-41. DOI: 10.1016/j.jfca.2014.12.024

98. Georgiou, Danezis G. Elemental and isotopic mass spectrometry. In Pico Y, (ed), Advanced Mass Spectrometry for Food Safety and Quality, Comprehensive Analytical Chemistry. Amsterdam: Elsevier, 2015, 131-243.

99. Bressy FC, Brito GB, Barbosa IS, et al. Determination of trace element concentrations in tomato samples at different stages of maturation by ICP OES and ICP-MS following microwave-assisted digestion. Microchem J 2013;109:145-9. DOI: 10.1016/j.microc.2012.03.010

100. Wu B, Andersch F, Weschke W, et al. Diverse accumulation and distribution of nutrient elements in developing wheat grain studied by laser ablation inductively coupled plasma mass spectrometry imaging. Metallomics 2013;5(9):1276-84. DOI: 10.1039/c3mt00071k

101. Shaheen N, Ahmed MK, Islam MS, et al. Health risk assessment of trace elements via dietary intake of 'non-piscine protein source' foodstuffs (meat, milk and egg) in Bangladesh. Environ Sci Pollut Res 2016;23(8):7794-806. DOI: 10.1007/s11356-015-6013-2

102. Guérin T, Chekri R, Vastel C, et al. Determination of 20 trace elements in fish and other seafood from the French market. Food Chem 2011;127(3):934-42. DOI: 10.1016/j.foodchem.2011.01.061

103. Kelly SD, Bateman AS. Comparison of mineral concentrations in commercially grown organic and conventional crops-Tomatoes (Lycopersicon esculentum) and lettuces (Lactuca sativa). Food Chem 2010;119(2):738-45. DOI: 10.1016/j.foodchem.2009.07.022

104. Caroli S (ed). The determination of chemical elements in food: applications for atomic and mass spectrometry. Hoboken NY: Wiley, 2007.

105. Goullé JP, Mahieu L, Castermant J, et al. Metal and metalloid multi-elementary ICP-MS validation in whole blood, plasma, urine and hair: reference values. Forensic Sci Int 2005;153(1):39-44. DOI: 10.1016/j.forsciint.2005.04.020

106. Heitland $P$, Köster HD. Biomonitoring of 37 trace elements in blood samples from inhabitants of northern Germany by ICP-MS. J Trace Elem Med Biol. 2006;20(4):253-62. DOI: 10.1016/j.jtemb.2006.08.001

107. Rodushkin I, Engström E, Baxter DC. Isotopic analyses by ICP-MS in clinical samples. Anal Bioanal Chem 2013;405(9):2785-97. DOI: 10.1007/s00216-012-6457-x

108. Michalski R. Application of IC-MS and IC-ICP-MS in environmental research. Hoboken NY: Wiley, 2016.

109. Khan N, Jeong IS, Hwang IM, et al. Method validation for simultaneous determination of chromium, molybdenum and selenium in infant formulas by ICP-OES and ICP-MS. Food Chem 2013;141(4):356670. DOI: 10.1016/j.foodchem.2013.06.034

110. Nardi EP, Evangelista FS, Tormen L, et al. The use of inductively coupled plasma mass spectrometry (ICP-MS) for the determination of toxic and essential elements in different types of food samples. Food Chem 2009;112(3):727-32. DOI: 10.1063/1.3681979

111. Goullé JP, Saussereau E, Mahieu L, et al. Current role of ICP-MS in clinical toxicology and forensic toxicology: a metallic profile. Bioanalysis 2014;6(17):2245-59. DOI: 10.4155/bio.14.190

112. Ahmed SS, Santosh W. Metallomic profiling and linkage map analysis of early Parkinson's disease: a new insight to aluminum marker for the possible diagnosis. PLoS One 2010;5(6):e11252. DOI: 10.1371/journal.pone.0011252

113. Hozumi I, Hasegawa T, Honda A, et al. Patterns of levels of biological metals in CSF differ among neurodegenerative diseases. J Neurol Sci 2011;303(1):95-9. DOI: 10.1016/j.jns.2011.01.003

114. Rodushkin I, Ödman F, Olofsson R, et al. Determination of 60 elements in whole blood by sector field inductively coupled plasma mass spectrometry. J Anal At Spectrom 2000;15(8):937-44. DOI: 10.1039/B003561K 
115. Alimonti A, Bocca B, Emilio Mannella E, et al. Assessment of reference values for selected elements in a healthy urban population. Ann Ist Super Sanita 2005;41(2):181-7.

116. Sugiyama N, McCurdy E. The new Agilent 8900 ICP-QQQ provides improved performance and enhanced flexibility. Agilent ICP-MS Journal 2016, 66:2-3.

117. Sela H, Karpas Z, Zoriy M, Pickhardt C, Becker JS. Biomonitoring of hair samples by laser ablation inductively coupled plasma mass spectrometry (LA-ICP-MS). Int J Mass Spectrom 2007;261(2):199207. DOI: 10.1016/j.ijms.2006.09.018

118. Sussulini A, Becker JS. Application of laser microdissection ICP-MS for high resolution elemental mapping in mouse brain tissue: A comparative study with laser ablation ICP-MS. Talanta 2015;132:579-82. DOI: 10.1016/j.talanta.2014.10.001

119. Noël M, Christensen JR, Spence J, Robbins CT. Using laser ablation inductively coupled plasma mass spectrometry (LA-ICP-MS) to characterize copper, zinc and mercury along grizzly bear hair providing estimate of diet. Sci Total Environ 2015;529:1-9. DOI: 10.1016/j.scitotenv.2015.05.004

120. Hagmeyer S, Mangus K, Boeckers TM, Grabrucker AM. Effects of trace metal profiles characteristic for autism on synapses in cultured neurons. Neural Plas 2015;2015, Article ID 985083. DOI: $10.1155 / 2015 / 985083$

121. Pfaender S, Grabrucker AM. Characterization of biometal profiles in neurological disorders. Metallomics 2014;6(5):960-77. DOI: 10.1039/c4mt00008k

122. Kim NH, Hyun YY, Lee KB, Chang Y, Rhu S, Oh KH, Ahn C. Environmental heavy metal exposure and chronic kidney disease in the general population. J Korean Med Sci 2015;30(3):272-7. DOI: 10.3346/jkms.2015.30.3.272

123. Breton J, Daniel C, Dewulf J, Pothion S, Froux N, Sauty M, Thomas P, Pot B, Foligné B. Gut microbiota limits heavy metals burden caused by chronic oral exposure. Toxicol Lett 2013;222(2):132-8. DOI: 10.1016/j.toxlet.2013.07.021

124. Jaishankar M, Tseten T, Anbalagan N, Mathew BB, Beeregowda KN. Toxicity, mechanism and health effects of some heavy metals. Interdisciplin Toxicol 2014;7(2):60-72. DOI: 10.2478/intox-2014-0009

125. Michalke B, editor. Metallomics: Analytical Techniques and Speciation Methods. John Wiley \& Sons; 2016.

126. Bjørklund G. The role of zinc and copper in autism spectrum disorders. Acta Neurobiol Exp 2013;73:225-36.

127. Averill B, Elderedge P. Chemistry: Principles, Patterns, and Applications. Prentice Hall; 1st edition 2007.

128. Yasuda H, Yasuda Y, Tsutsui T. Estimation of autistic children by metallomics analysis. Sci Rep 2013;3. DOI: 10.1038/srep01199

129. Wright RO, Baccarelli A. Metals and neurotoxicology. J Nutr 2007;137(12):2809-13.

130. Fujiwara T, Morisaki N, Honda Y, Sampei M, Tani Y. Chemicals, nutrition, and autism spectrum disorder: a mini-review. Front Neurosci 2016;10. DOI: 10.3389/fnins.2016.00174

131. Delafiori J, Ring G, Furey A. Clinical applications of HPLC-ICP-MS element speciation: A review. Talanta 2016;153:306-31. DOI: 10.1016/j.talanta.2016.02.035

132. Hann S, Dernovics M, Koellensperger G. Elemental analysis in biotechnology. Curr Opin Biotechnol 2015;31:93-100. DOI: 10.1016/j.copbio.2014.08.008

133. Swart C, Jakubowski N. Update on the status of metrology for metalloproteins. J Anal At Spectrom 2016;31(9):1756-65. DOI: 10.1039/C6JA00181E

134. Haglock-Adler CJ, Strathmann FG. Simplified sample preparation in the simultaneous measurement of whole blood antimony, bismuth, manganese, and zinc by inductively coupled plasma mass spectrometry. Clin Biochem 2015;48(3):135-9. DOI: 10.1016/j.clinbiochem.2014.11.012 
135. Harrington JM, Young DJ, Fry RC, Weber FX, Sumner SS, Levine KE. Validation of a metallomics analysis of placenta tissue by inductively-coupled plasma mass spectrometry. Biol Trace Elem Res 2016;169(2):164-73. DOI: 10.1007/s12011-015-0431-3

136. Mayo Medical Laboratories. Rochester Test Catalog, 2016 Online Test Catalog. Mayo Clinic. http://www.mayomedicallaboratories.com/test-catalog (21 Sep. 2016, date last accessed)

137. Böhlke JK, De Laeter JR, De Bievre P, Hidaka H, Peiser HS, Rosman KJ, Taylor PD. Isotopic compositions of the elements, 2001. J Phys Chem Ref Data 2005 1;34(1):57-67. DOI: 10.1063/1.1836764 